\title{
The effect of flow pulsation on the heating performance of panel radiators in central heating systems: CFD analysis
}

\author{
M. Embaye, R. K. Al-Dadah \& S. Mahmoud \\ School of Mechanical Engineering, University Of Birmingham, UK
}

\begin{abstract}
This research investigates the effect of pulsed flow input on the energy consumption of panel radiators in hydronic central heating systems. CFD modelling of a panel radiator was developed using the conjugate heat transfer module in COMSOL Multiphysics software. The radiator used was of single finned radiator (type 11) with the dimensions of $500 \mathrm{~mm}$ long and $300 \mathrm{~mm}$ high. The CFD results performed in this paper were compared to published experimental work found in literature showing good agreement with maximum deviation of $2.14 \%$ in the heat output. A wide range of input pulsating flows were investigated in terms of velocity amplitude (from $0.035 \mathrm{~m} / \mathrm{s}$ to $0.05 \mathrm{~m} / \mathrm{s}$ ) and frequency (from $0.052 \mathrm{rad} / \mathrm{s}$ to $0.209 \mathrm{rad} / \mathrm{s}$ ) while the flow input temperature remains constant. The simulation results showed that compared to constant flow operating condition, the use of pulsed flow can reduce the energy consumption of panel radiators by up to $20 \%$ while maintaining the same radiator surface temperature. Such results highlight the potential of using pulsed flow to reduce the energy consumption of central heating systems in buildings.
\end{abstract}

Keywords: energy saving, CFD models, COMSOL Multiphysics, constant flow, flow pulsation, temperature and heat output.

\section{Introduction}

Effective energy utilization has high impact on energy consumption and greenhouse gas emission. In developed countries, published data showed buildings energy consumption is around $50 \%$ of the total energy used Novoselac [1]. The demand of European Union to reduce energy consumption by $20 \%$ before 2020 is adopted by the member states and enhancing the efficiency of 
domestic central heating systems is an important factor in achieving this target [2-4]. Heat transfer can be improved using various methods which can be classified as passive or active. The passive methods of heat transfer enhancement do not require direct application of external power, such as extended surface, vertex generator and nanofluids. The active enhancement techniques require continuous supply of power to maintain the enhancement which includes surface vibration, magnetic fields, and mechanical mixing (Khaled [5]).

Considerable research has been carried out to improve the performance of domestic central heating systems covering the various heat sources and heating appliances. Heat sources include Heat pump, District heating, Boiler (Combi boiler, Condensing boiler), and CHP (Combined Heat and Power). Heating appliances include panel radiators with and without convective fins, floor heating and air heating. Figure 1 describes the major components of a central heating system with various types of appliances and heat sources.

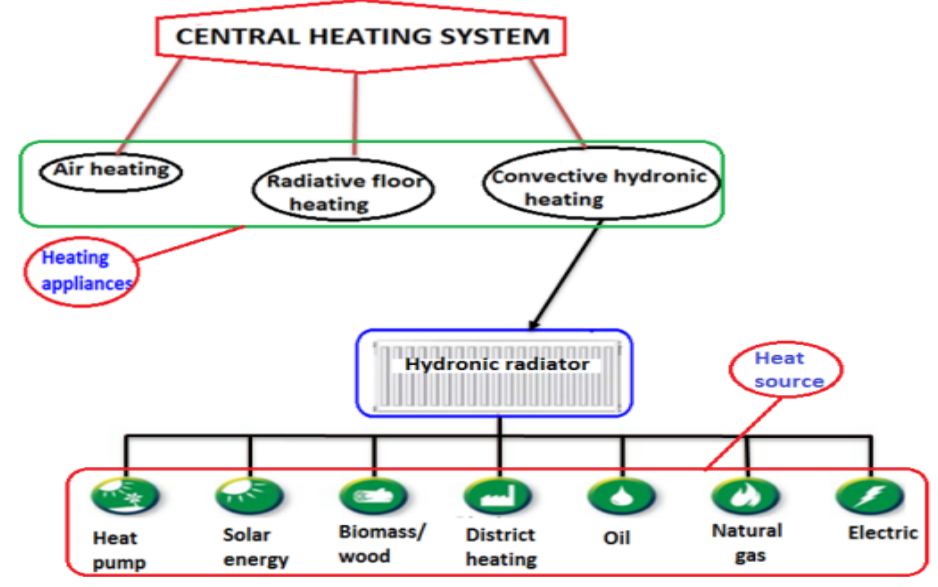

Figure 1: The central heating appliance and the heat source.

Hydronic panel radiators are the most commonly used heat emitter appliance in Europe due to their compact design and ease of installation. Research has been carried out to enhance the central heating system by increasing air flow on the panel radiator heat transferring surfaces (Myhren and Halberg [4]). Coating the wall behind the radiator with high emissivity (smooth black surface) paint resulted in improving the heat output from panel radiators (Bangert [6]). Also, placing two high emissivity metals in the interior side of the double panel radiator can enhance the heat output of the panel radiators (Beck et al. [7]). Smart control management of central heating system can also play important role in reducing energy consumption and improve the comfort temperature of the occupants.

Flow pulsation is a method of heat transfer enhancement applied for various industrial applications including heat exchangers, pulse combustors, electronic cooling devices, cooling system of nuclear reactors as described by Li et al. [8]. 
Sailor et al. [9] conducted a series of experiments to compare the heat transfer enhancement for pulsed air jet and steady flow air jet. They showed that up to $50 \%$ heat transfer enhancement can be achieved for the pulsed jet relative to steady flow jet. Chen and Zhao [10] carried out a study to investigate the heat transfer enhancement of shell and tube heat exchanger using pulsated flow and found that by optimizing the flow frequency, the capacity of heat transfer in the heat exchanger can be increased by up to $60 \%$.

This work aims to investigate the heat transfer enhancement due to flow pulsation relative to constant flow scheme in panel radiators of hydronic central heating system.

\section{CFD simulation}

The CFD simulation of the 3D panel radiators were carried out using conjugate heat transfer module in COMSOL Multiphysics software [11, 12]. Reynolds Average Navier Stokes (RANS) equations with the k- $\varepsilon$ turbulence model were used. The Navier Stokes equations in terms of the continuity, momentum and energy equations are shown in eqns. (1), (2) and (3) respectively.

$$
\begin{aligned}
& \rho \frac{\partial u}{\partial t}+\rho(u . \nabla) u=\nabla \cdot\left[-p I+\left(\mu+\mu_{T}\right)\right. \\
& \left.\left(\nabla u+(\nabla u)^{T}\right)-\frac{2}{3}\left(\mu+u_{T}\right)(\nabla \cdot u) I-\frac{2}{3} \rho \kappa I\right]+F
\end{aligned}
$$

where

$$
\begin{gathered}
\mu_{T}=\rho C_{\mu} \frac{\kappa^{2}}{\varepsilon} \\
\frac{\partial \rho}{\partial t}+\nabla \cdot(\rho V)=0 \\
\rho C_{p} \frac{d T}{d t}+\rho C_{p} V \cdot \nabla T=\nabla \cdot(k \nabla T)+Q
\end{gathered}
$$

The values for the turbulence model of $\kappa$ (turbulent kinetic energy), $\varepsilon$ (turbulent dissipation rate), and the pressure are calculated using eqns. (4), (5), and (6) respectively.

$$
\begin{aligned}
& \rho \frac{\partial \kappa}{\partial t}+\rho(u . \nabla) \kappa=\nabla\left[\left(\mu+\frac{\mu_{T}}{\sigma_{\kappa}}\right) \nabla \kappa\right]+p_{\kappa}-\rho \varepsilon \\
& \rho \frac{\partial \varepsilon}{\partial t}+\rho(u . \nabla) \varepsilon=\nabla\left[\left(\mu+\frac{\mu_{T}}{\sigma_{\varepsilon}}\right) \nabla \varepsilon\right] \\
&+C_{\varepsilon 1} \frac{\varepsilon}{\kappa} p_{\kappa}-C_{\varepsilon 2} \rho \frac{\varepsilon^{2}}{\kappa}
\end{aligned}
$$




$$
\begin{array}{r}
p_{\kappa}=\mu_{T}\left[\nabla u:\left(\nabla u+(\nabla u)^{T}\right)-\frac{2}{3}(\nabla \cdot u)^{2}\right] \\
-\frac{2}{3} \rho \kappa \nabla \cdot u
\end{array}
$$

where: $\rho, \mathrm{C}_{\mathrm{p}}, \mathrm{T}, \mathrm{u}, \mathrm{p}, \mathrm{Q}, \mathrm{I}, \mathrm{F}, \varepsilon, \mu \mathrm{T}, \mu, \mathrm{pk}, \mathrm{k}, \mathrm{V}$ and $\kappa$ are density, specific heat capacity, temperature, vector velocity, pressure and heat source other than viscous, identity matrix of [3*3], total force acting per volume $[\mathrm{N} / \mathrm{m} 3]$, the turbulence dissipation rate, turbulence dynamic viscosity, dynamic viscosity, turbulent kinetic pressure, heat conductivity, volume and the turbulence kinetic energy respectively.

Figure 2 shows the 3D model of panel radiator (type 11) set to top-bottom opposite end (TBOE) with the selected mesh concentration and table 1 presents the thermal properties of the materials used in the panel radiator. The panel radiator model included the rectangular ducts, $15 \mathrm{~mm}$ side with thickness of $1 \mathrm{~mm}$, and fins $270 \mathrm{~mm}$ high with thickness of $0.5 \mathrm{~mm}$. The radiator model was meshed based on the geometrical structure of each component; swept rectangular mesh was generated for the fins (478080 element numbers) and tetrahedral mesh was selected for the water domain and the flow channels (1759121 element numbers). Assumptions were considered to simulate the panel radiator in both pulsed flow and constant flow cases.

- Convection cooling was assumed on the external surface (air side surface) of the radiator.

- The hot water inlet supply temperature was assumed to be constant.

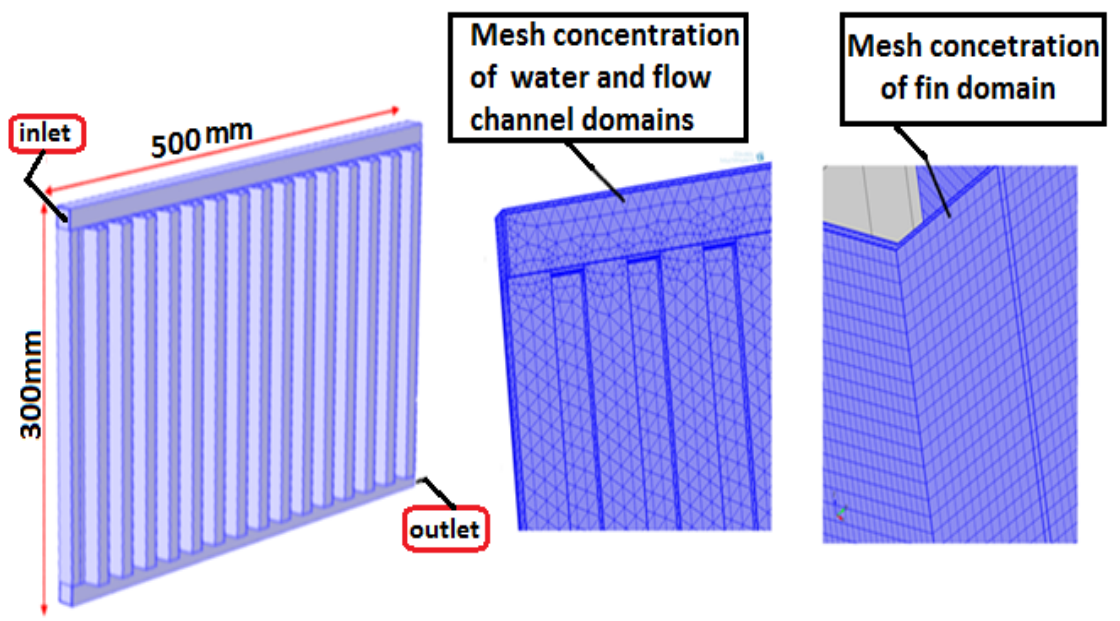

Figure 2: Dimensions of the panel radiator geometry and the mesh concentration. 
Table 1: The material properties hydronic panel radiator and water domains.

\begin{tabular}{|l|l|l|l|l|}
\hline $\begin{array}{l}\text { Domain } \\
\text { type }\end{array}$ & Materials type & $\begin{array}{l}\mathbf{K} \\
{[\mathbf{W} / \mathbf{m} \cdot \mathbf{K}]}\end{array}$ & $\begin{array}{l}\mathbf{C}_{\mathbf{p},} \\
{[\mathbf{J} / \mathbf{k g} \cdot \mathbf{m}]}\end{array}$ & $\begin{array}{l}\boldsymbol{\rho} \\
{\left[\mathbf{k g} / \mathbf{m}^{3}\right]}\end{array}$ \\
\hline $\begin{array}{l}\text { Fluid } \\
\text { medium }\end{array}$ & incompressible Water & 0.58 & 4180 & 1000 \\
\hline Channels & Steel (AISI 4340) & 44.5 & 475 & 7850 \\
\hline Fins & Steel (AISI 4340) & 44.5 & 475 & 7850 \\
\hline
\end{tabular}

\section{CFD simulation results of the radiator at constant hot water inlet flow rate}

The radiator used in this research was of single finned radiator (type 11) at constant hot water inlet mass flow rate of $0.00571 \mathrm{~kg} / \mathrm{s}$. The radiator was simulated at constant inlet temperature of $75^{\circ} \mathrm{C}$ and ambient temperature of $20^{\circ} \mathrm{C}$. Figure 3(a) shows the local temperature distribution of the radiator at steady state condition and Figure 3(b) shows the heat output, the hot water outlet temperature, and the average surface temperature of the panel radiators with time.
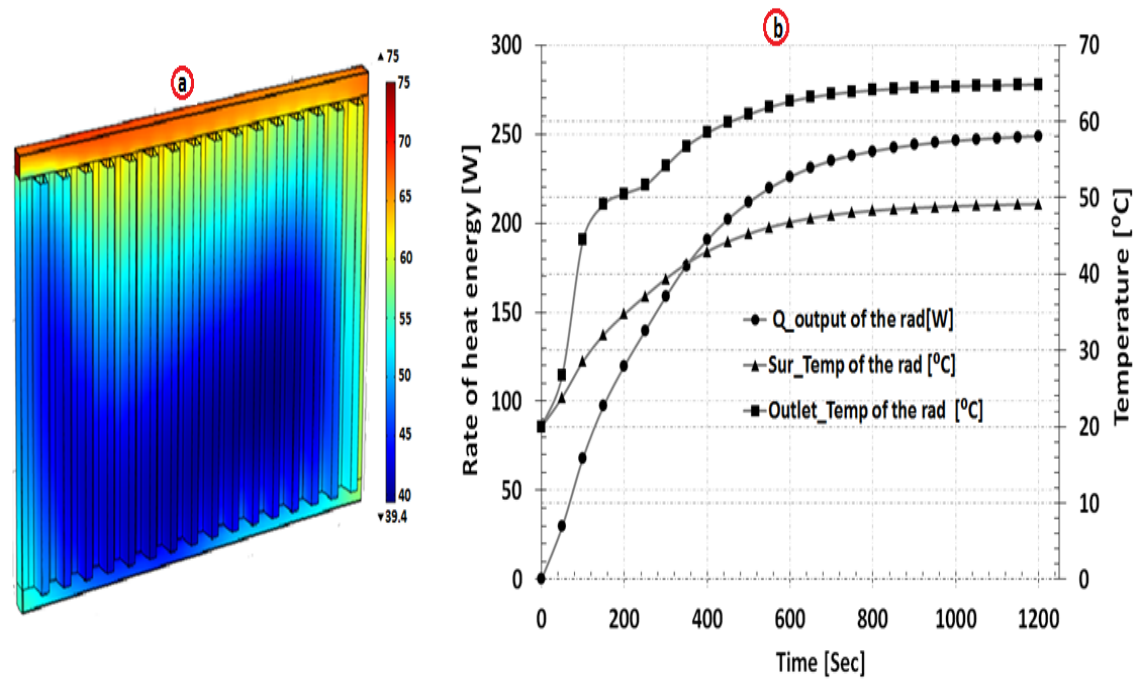

Figure 3: $\quad$ Panel radiator type 11 at constant flow scenario (a) local surface temperature distribution $\left({ }^{\circ} \mathrm{C}\right)$ and $(b)$ average surface temperature, water outlet temperature, and heat output from the radiator.

As shown in figure 3 the steady state surface temperature for simulated radiator is close $\left(50^{\circ} \mathrm{C}\right)$ which was the target surface temperature for this work. Tables 2 shows the close agreement between the predicted steady state CFD 
results and those obtained from the experimental work of Berkan [14] in terms of the rate of heat output, radiator surface temperature and the water outlet temperature.

Table 2: $\quad$ The CFD and experimental results and input value of the single panel radiator with attached fins.

\begin{tabular}{|l|l|l|l|}
\hline Specifications & CFD & Exp & Diff \% \\
\hline Flow rate (kg/s) & 0.02285 & 0.0228 & \\
\hline Ambient temperature $\left({ }^{\mathbf{0}} \mathbf{C}\right)$ & 19.89 & 19.89 & \\
\hline Inlet temperature $\left({ }^{\mathbf{0}} \mathbf{C}\right)$ & 74.76 & 74.76 & \\
\hline Outlet temperature $\left({ }^{\mathbf{0}} \mathbf{C}\right)$ & 64.83 & 64.71 & 0.15 \\
\hline Mean temperature $\left({ }^{\mathbf{0}} \mathbf{C}\right)$ & 69.79 & 69.76 & 0.043 \\
\hline Excess temperature $\left({ }^{\circ} \mathbf{C}\right)$ & 49.15 & 49.76 & 1.20 \\
\hline Heat output from the radiator $(\mathbf{W})$ & 992.088 & 968.42 & 2.44 \\
\hline
\end{tabular}

\section{Effect of input flow pulsation on radiator heat output}

The panel radiator type 11 was simulated using input pulsed flow with varying Strouhal number eqn. (7) from 0.23 to 0.65 and varying Reynolds number eqn. (13) from 0 to 1838.4 while the inlet hot water temperature and ambient temperature were fixed at $75^{\circ} \mathrm{C}$ and $20^{\circ} \mathrm{C}$ respectively.

$$
\begin{aligned}
S t & =\frac{f \cdot L}{V} \\
\mathrm{Re} & =\frac{V \cdot d_{h}}{v}
\end{aligned}
$$

where

$$
d_{h}=\frac{4 \cdot A}{2 P e r}
$$

where: St, f, L, V, $\mathrm{d}_{\mathrm{h}}, \mathrm{v}, \mathrm{A}$ and Per are the Strouhal number, frequency, characteristics length, flow velocity, hydraulic diameter, kinetic viscosity of water, cross sectional are of the inlet, and the inlet perimeter of the radiator respectively.

Figure 4 shows the profile of the pulsed hot water inlet velocity to the radiator model. Table 3 shows the various flow amplitudes; and various average hot water mass flow rate at constant frequency of $0.033 \mathrm{~Hz}$. The flow amplitude that produced the best heat output was selected for further simulations using various flow frequencies. Figure 5 shows the rate of heat output and the energy ratio of the pulsed radiator at various flow amplitudes. The specific heat output is the ratio of heat output to the supplied hot water mass flow rate eqn. (9). The operating scenario that gives highest energy ratio indicates the best heat output performance of the radiator at the selected flow amplitudes. The energy saving is expressed using eqn. (10). 


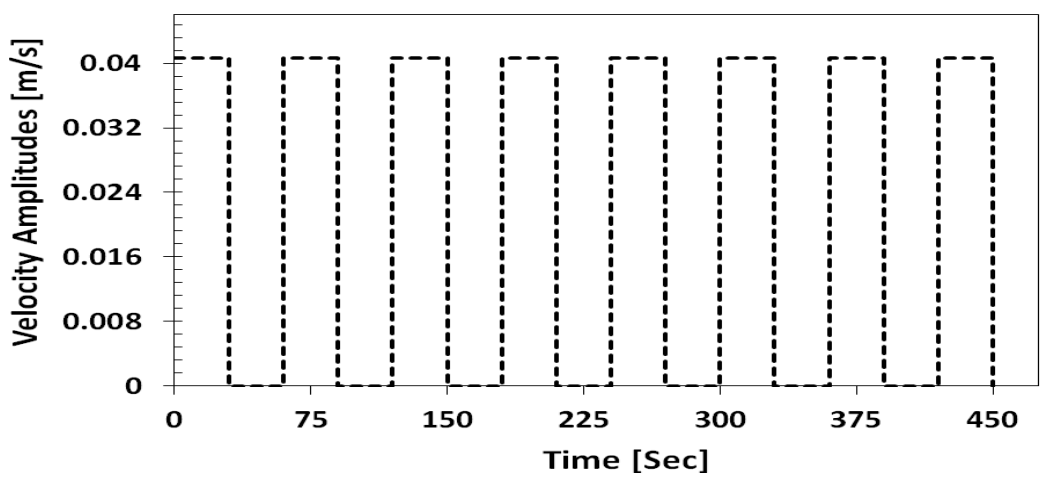

Figure 4: The profile of used inlet mass flow rate of the radiator at the pulsed flow strategy.

Table 3: Pulsed flow amplitudes and average mass flow rate used at constant frequency of $0.033 \mathrm{~Hz}$.

\begin{tabular}{|c|c|}
\hline Amplitudes $[\mathrm{m} / \mathrm{s}]$ & Average mass flow rate $[\mathrm{kg} / \mathrm{s}]$ \\
\hline 0.03552 & 0.003997 \\
\hline 0.0406 & 0.004568 \\
\hline 0.04568 & 0.005138 \\
\hline 0.05074 & 0.005710 \\
\hline
\end{tabular}

$$
\begin{gathered}
\mathrm{Sp} \cdot \mathrm{Q}_{\text {output }}=\frac{\mathrm{Q}_{\text {outout }}}{\dot{m}_{\text {input }}} \\
\% E S=\left(\frac{\dot{m}_{C F}-\dot{m}_{P F}}{\dot{m}_{C F}}\right) * 100
\end{gathered}
$$

where: Sp. Q output $_{\text {is }}$ the specific heat output $(\mathrm{W} / \mathrm{kg}), \mathrm{Q}_{\text {output }}$ is the rate of heat output from the radiator (W), $\dot{m}$ is the inlet mass flow rate $(\mathrm{kg} / \mathrm{s}), \mathrm{ES}$ is the energy saving, CF is constant flow, PF pulsed flow.

It is clear from figure 5(a) that the highest specific heat output is achieved with pulsed flow at velocity amplitude of $0.0406 \mathrm{~m} / \mathrm{s}$ which gives average mass flow rate of $0.004568 \mathrm{~kg} / \mathrm{s}$. This pulsed amplitude with highest specific heat output was selected for further investigation at various operating flow frequency. Figure 6 shows the heat output at various flow frequencies using flow amplitude of $0.0406 \mathrm{~m} / \mathrm{s}$. 

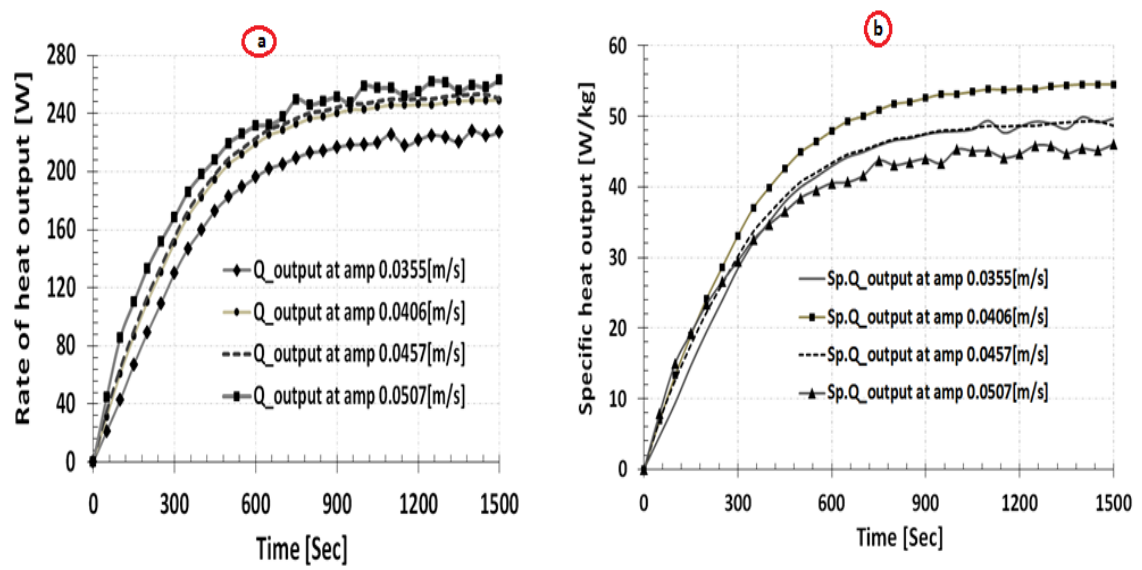

Figure 5: (a) Rate of heat output of pulsed radiator at flow frequency of $0.209 \mathrm{rad} / \mathrm{s}$ and (b) rate of specific heat output pulsed radiator at flow frequency of $0.209 \mathrm{rad} / \mathrm{s}$.

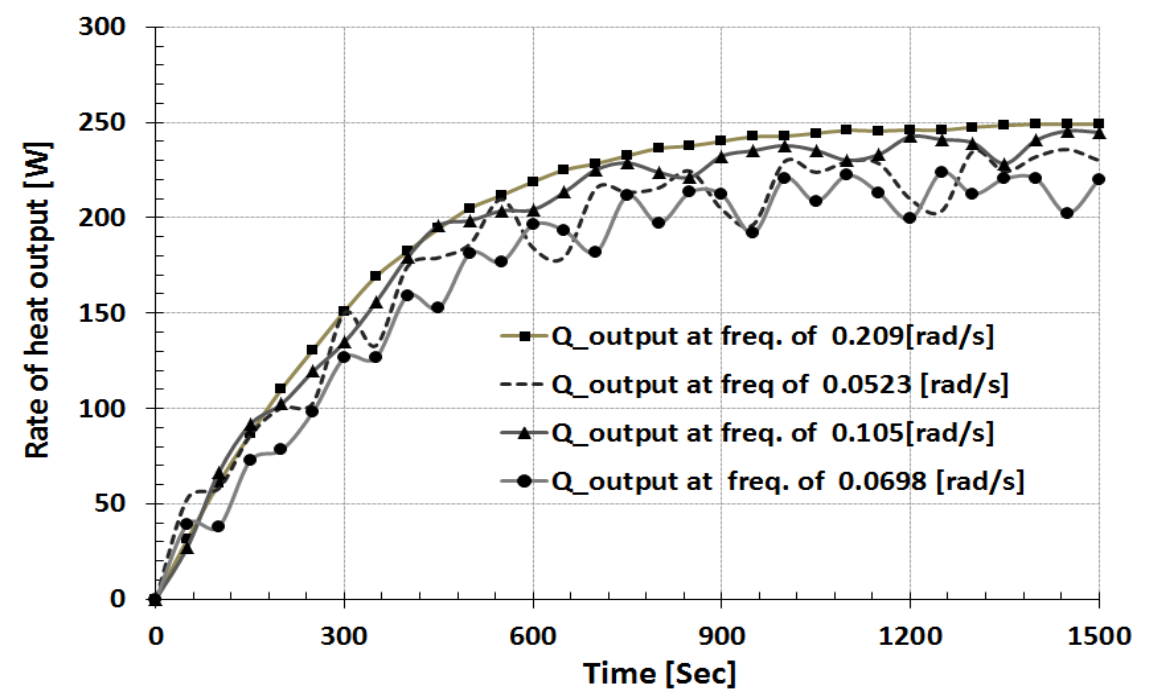

Figure 6: The heat output of the radiator using various frequencies at constant amplitude of $0.04060 \mathrm{~m} / \mathrm{s}$.

As shown in figure 6 the highest heat output was produced at operating frequency of $0.209 \mathrm{rad} / \mathrm{s}(0.033 \mathrm{~Hz})$ and flow amplitude of $0.0406 \mathrm{~m} / \mathrm{s}$. Figure 7 shows the local temperature contour, the average surface temperature of the (excess temperature of the radiator), the heat output performance and the water outlet temperature of the panel radiator at the best amplitude and frequency. It is 
clearly shown that; the average surface temperature of the panel radiator is directly proportional to the heat output performance of the radiator. The specific heat output of the pulsed flow radiator operating at the best flow amplitude and flow frequency was compared with the specific heat output of constant inlet mass flow scenario. The enhancement of heat transfer or heat output of the heat emitter (hydronic heating radiator) was estimated based on the specific heat output eqn. (9) and the \% of energy saving can also calculated using eqn. (10). Higher specific heat output indicates higher heat emitting performance from the radiator. Figure 8 shows the specific heat output and the enhanced area of the specific heat output due to the pulsed flow compared to the constant flow radiator (traditionally operating radiator).
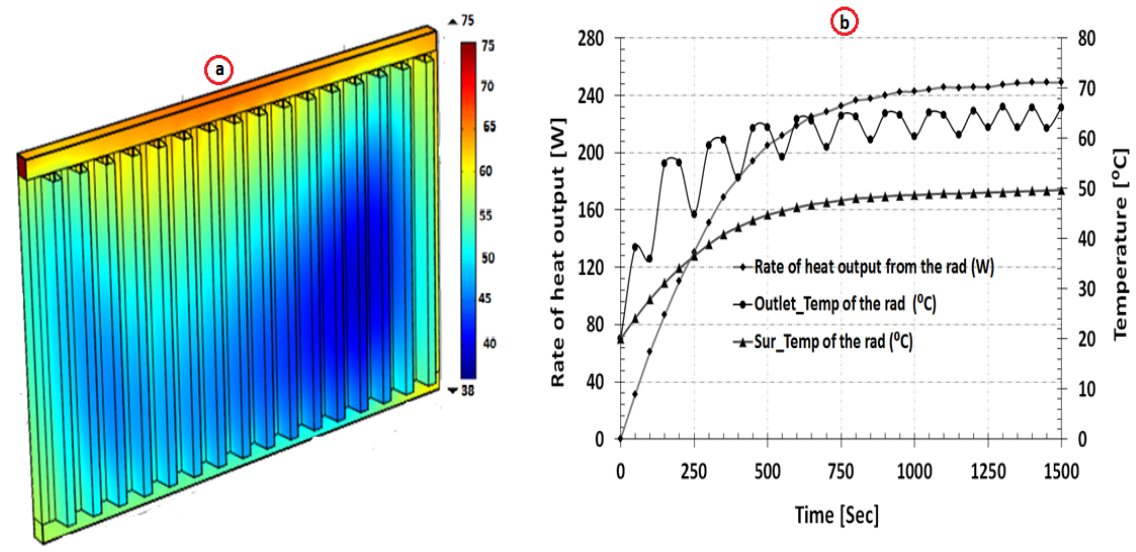

Figure 7: Panel radiator type 11 at pulsed flow scenario (a) local surface temperature distribution $\left({ }^{\circ} \mathrm{C}\right)$ and $(\mathrm{b})$ average surface temperature; water outlet temperature; heat output from radiator.

Figure 8 shows the enhanced heat output (shaded area) leading to up to $20 \%$ saving in the energy consumption of the panel radiator used. In addition to the heat output (energy saving) thermal inertia of the heat exchanger (panel radiator) also be improved. This saving can be attributed to the improvement in the heat transfer coefficient on the internal surface of the radiator due to the flow mixing by pulsation. Figure 9 shows the local velocity stream for the internal walls of radiator channels for both the constant flow case (a) and the pulsed flow case (b). It can be seen that higher velocity distribution were observed for the pulsed flow case compared to that of the constant flow case particularly at the vertical channels. Such results highlight the potential of using flow pulsation in panel radiators for reducing energy consumption in hydronic centrally heated buildings. 


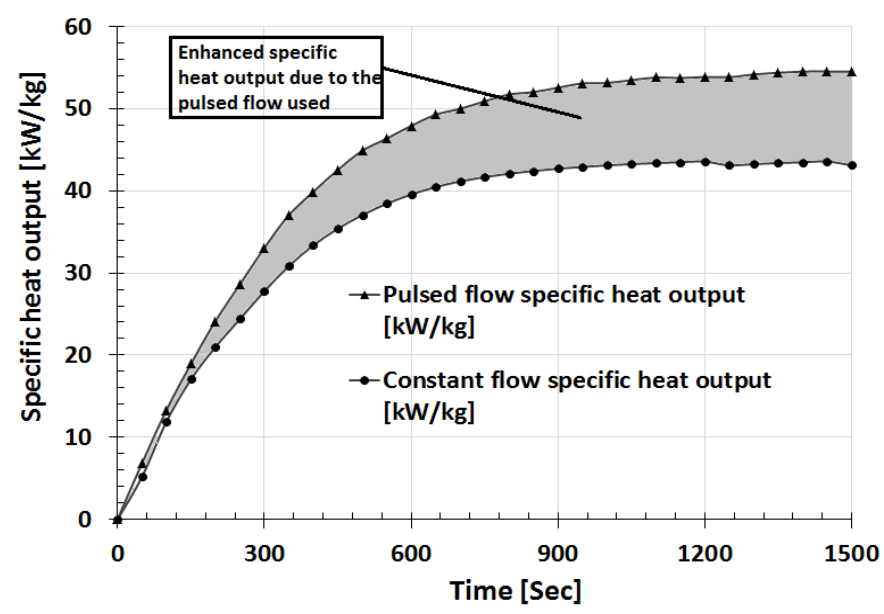

Figure 8: Enhanced specific heat output of the panel radiator due to the pulsed flow case compared to the constant flow case.
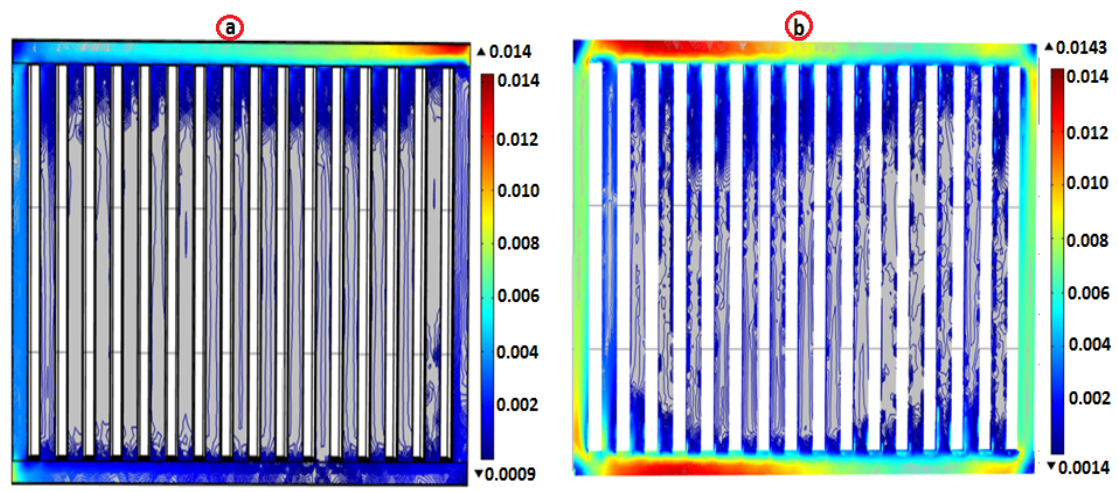

Figure 9: (a) local velocity $(\mathrm{m} / \mathrm{s})$ distribution of internal wall channels at constant flow, (b) local velocity $(\mathrm{m} / \mathrm{s})$ distribution of internal wall channels at pulsed flow.

\section{Conclusions}

In this work, flow pulsation technique was used to enhance the heat transfer performance of panel radiators used in central heating systems through CFD modelling. The simulation results for constant flow input case were compared to published experimental work showing good agreement with maximum deviation of $2.14 \%$ in the heat output.

A wide range of input pulsating flows with constant input temperature in terms of velocity amplitude (from $0.035 \mathrm{~m} / \mathrm{s}$ to $0.05 \mathrm{~m} / \mathrm{s}$ ) and frequency (from $0.052 \mathrm{rad} / \mathrm{s}$ to $0.209 \mathrm{rad} / \mathrm{s}$ ) were investigated. Results showed that up to $20 \%$ 
reduction in the energy consumption can be achieved without affecting the radiator surface temperature. This improvement can be attributed to the increased flow velocity values inside the radiator due to the pulsation effect particularly in the areas behind the vertical fins. This highlights the potential of using pulsed flow to enhance the heat transfer of panel radiators and reduce the energy consumption of central heating systems in buildings.

\section{References}

[1] Novoselac, A., Combined airflow and energy simulation program for building mechanical system design, PhD dissertation, USA, 2005, online. http://www.ce.utexas.edu/prof/Novoselac/Atila_Novoselac_thesis.pdf

[2] LEVOLUX, Designed to control online:

http://www.levolux.com/L_Misc/40\%25_energy_consumption.htm

[3] Dineen, D. and Gallachóir, B.P.Ó., Modelling the impacts of building regulations and a property bubble on residential space and water heating. Energy Buildings, 43, pp. 166-178, 2011.

[4] Myhren, J. A. and Halberg, S., Design Consideration with ventilationradiators comparisons to traditional two-panel radiators. Energy and buildings, 41, pp. 92-100, 2009.

[5] Khaled, A.R.A., Heat transfer enhancement due to properly managing the distribution of the heat flux. Energy Conversion and Management, 53, 247-258, 2012.

[6] Bangert, K., Radiator heat transfer augmentation by changes to wall surface roughness and emissivity. The University of Sheffield, 2010.

[7] Beck, S.M.B., Grinsted, S.C., Blakey, S.G. and Worden, K., Novel design for panel radiators. Applied Thermal Engineering, 24, pp. 1291-1300, 2004.

[8] Li, G., Zheng, Y., Hu, G. and Zhang, Z., Experimental investigation on heat transfer enhancement from an inclined heated cylinder with constant heat input power in infrasonic pulsating flows. ETF, 2013.

[9] Sailor, D.J., Rohli, D.J. and Fu, Q., Effect of variable duty cycle flow pulsations on heat transfer enhancement. Heat and fluid flow, 43, pp. 137-146, 1999.

[10] Chen, Y. and Zhao, J., Applications of the Strong Heat Transformation by pulse flow in the Shell and tube heat exchanger. HVAC Technologies for Energy Efficiency, 06, pp. 11-105, 2006.

[11] COMSOL Multiphysics version 4.3.

[12] Yakah, N., Heat exchanger design for a Solar Gas-Turbine Power Plant. RTM industrial engineering and management Stockholm, 2012.

[13] Myhren, J. A. and Holmberg, S., Flow patterns and thermal comfort in a room with panel, floor and wall heating. Energy and Buildings, 40, pp. 524-536, 2008.

[14] Berkan, A., Simulation of the heater test room defined by EN442 standard and virtual testing of different type of heaters (PhD thesis), 2011 Online. http://library.iyte.edu.tr/tezler/doktora/makinamuh/T000858.pdf 